\title{
Effect of supplementation of different levels of selenium as nanoparticles/sodium selenite on blood biochemical profile and humoral immunity in male Wistar rats
}

\author{
S. J. Bunglavan ${ }^{1}$, A. K. Garg ${ }^{1}$, R. S. Dass ${ }^{1}$ and Sameer Shrivastava ${ }^{2}$
}

1. Division of Animal Nutrition, Indian Veterinary Research Institute, Izatnagar, Uttar Pradesh, India; 2. Division of Animal Biotechnology, Indian Veterinary Research Institute, Izatnagar, Uttar Pradesh, India.

Corresponding author: S. J. Bunglavan, e-mail: surej138@gmail.com,

AKG: akgivri@gmail.com, RSD: rsdass.ivri@gmail.com, SS: sameer_vet@rediffmail.com

Received: 31-07-2014 Revised: 06-11-2014 Accepted: 11-11-2014, Published online: 11-12-2014

doi: 10.14202/vetworld.2014.1075-1081. How to cite this article: Bunglavan SJ, Garg AK, Dass RS, Shrivastava S (2014) Effect of supplementation of different levels of selenium as nanoparticles/sodium selenite on blood biochemical profile and humoral immunity in male Wistar rats, Veterinary World 7(12): 1075-1081.

\begin{abstract}
Aim: To study the effect of supplementation of different levels of selenium as nanoparticles/sodium selenite on blood biochemical profile and humoral immunity in male Wistar rats.

Materials and Methods: The experimental research was conducted at Division of Animal Nutrition, Indian Veterinary Research Institute, Izatnagar. 63 male Wistar rats were divided into 9 equal groups on the basis of their mean body weight (BW) (124.3 $\pm 3.1 \mathrm{~g} \mathrm{BW)} \mathrm{following} \mathrm{completely} \mathrm{randomized} \mathrm{design.} \mathrm{Experimental} \mathrm{feeding} \mathrm{was} \mathrm{similar} \mathrm{in} \mathrm{all} \mathrm{the} \mathrm{groups} \mathrm{except}$ for the source and level of selenium (Se) in the diet. While Group 1 (control) was fed a basal diet with no Se supplementation, in Groups 2 and 3, 150 ppb Se was supplemented either as sodium selenite or Se nanoparticles, respectively. In Groups 4, 5, 6 and 7, Se was supplemented as its nanoparticles at 50\%, 25\%, 12.5\% and 6.25\% levels respectively i.e. at 75 ppb, 37.5 ppb, 18.75 ppb and 9.375 ppb levels respectively. In Groups 8 and 9, 300 ppb Se was supplemented either as Se nanoparticles or sodium selenite, respectively. Experimental feeding was conducted for a period of 91 days. At the end of the experimental trial, blood samples were collected to analyze the blood serum biochemical profile (serum glucose, serum total protein (TP), serum albumin, serum globulin, serum albumin: globulin ratio [A:G ratio], serum total cholesterol) and humoral immunity.

Results: The levels of serum glucose, serum ТP and serum albumin were comparable ( $>0.05)$ among the nine groups of male Wistar rats. The mean serum total cholesterol was significantly $(\mathrm{p}<0.001)$ lowered in all the Se supplemented Wistar rats compared to the control group. The mean serum globulin level was significantly $(\mathrm{p}<0.05)$ higher and A:G ratio was significantly $(\mathrm{p}<0.05)$ lowered in Group 3 (supplemented with $150 \mathrm{ppb}$ selenium nanoparticles) followed by Groups 2, 4, 5, 6 , 8, and 9 as compared to the control group. The mean serum antibody titer was significantly $(\mathrm{p}<0.001)$ higher in all the Se supplemented groups with the highest value in Group 3 (supplemented with 150 ppb selenium nanoparticles) followed by Groups 4, 5, 8 and 9 compared to the control group.
\end{abstract}

Conclusion: Supplementation of selenium nanoparticles at the level of $150 \mathrm{ppb}$ gave the best performance in terms of increased serum globulin level, reduced A:G ratio, and improved humoral immune status in male Wistar rats.

Keywords: humoral immunity, nanoparticles, selenium, serum cholesterol, serum globulin, serum glucose, serum total protein, Wistar rats.

\section{I ntroduction}

Selenium, which was earlier classified as a toxic element, has now been proved to be an essential mineral required for proper health, immunity, and reproductive functions of animals [1]. More than thirty different selenium containing enzymes have been defined in animals [2]. It has an important role in the generation of resistance to disease either through enhancing the immune response, leukocyte function or specific immunity of the animals [3]. It is a component of glutathione peroxidase (POD) enzyme [4], which destroys free radicals in the cytoplasm [5]. It has been demonstrated that selenium protects the tissues against oxidative damage [6]. Selenium improves immune responses [7] as it is required for the development and

Copyright: The authors. This article is an open access article licensed under the terms of the Creative Commons Attributin License (http:// creative commons.org/licenses/by/2.0) which permits unrestricted use, distribution and reproduction in any medium, provided the work is properly cited. expression of non-specific humoral and cell-mediated immune responses. Selenium is also a component of the enzyme Type I deiodinase, which is required for the conversion of thyroxine $\left(\mathrm{T}_{4}\right)$ into more active tri-iodothyronine $\left(\mathrm{T}_{3}\right)$ [8]. Selenium deficiency results in immune suppression and reduced resistance to infection, neutrophil function, antibody production, proliferation of $\mathrm{T}$ and $\mathrm{B}$ cells in response to mitogens, and cytodestruction by T-lymphocytes and natural killer cells. Probably the effects on function of glutathione POD and ability to interact with cell membranes represent the immuno-enhancing role of selenium $[9,10]$.

Presently, sodium selenite is the usual Se source as a supplement in animal feeds [11]. However, it has the disadvantage in animal nutrition that it is a potential toxin at higher dietary levels [12], has lower absorption efficiency [11] and exhibits pro-oxidation defects [12]. Moreover being carcinogenic in nature its use is being discouraged. In recent years, organic 
forms of Se such as Se enriched yeast [13] or selenomethionine [14] have also been tried and were reported to be a better and safer source of Se for animal feeding as compared to inorganic Se sources [15]. Elemental selenium powder in the redox state of 0 is not soluble and generally considered to be biologically inert. Recently, nanotechnology holds promise for medication and nutrition because materials at the nanometer dimension exhibit novel properties such as high-surface activity, great specific surface area, high catalytic efficiency, a lot of surface active centers, and a strong adsorbing ability [16-18]. Previous researches have reported that Se nanoparticles possessed comparable efficiency to selenite, selenomethionine, and methylselenocysteine in up regulating selenoenzymes in mice and rats in having higher bioavailability and lower acute toxicity [19-22]. However, reports on the effect of Se nanoparticles on the blood serum biochemical profile and humoral immune response of the animals are scanty.

Hence, an experiment was designed to study the effect of supplementation of different levels of selenium as selenium nanoparticles/sodium selenite on blood biochemical profile and humoral immunity in male Wistar rats.

\section{Materials and Methods}

Ethical approval

The present study was conducted at Division of Animal Nutrition, Indian Veterinary Research Institute, Izatnagar. The experimental protocol was approved by Institutional Animal Ethics Committee.

\section{Animals, selection and grouping}

Sixty-three male Wistar rats were procured from Laboratory Animal Resource Section of Indian Veterinary Research Institute, Izatnagar. For acclimatizing to the new environment, these animals were maintained for 7 days on a standard diet comprising of concentrate mixture before the start of the proper experiment. These animals were then divided into nine groups of 7 animals in each group on the basis of their mean body weight (BW) $(124.3 \pm 3.1 \mathrm{~g} \mathrm{BW})$ following completely randomized design.

\section{Housing and management}

All the experimental animals were housed in a well-ventilated room. Strict management and hygienic practices were adopted throughout the experimental period. Clean drinking water was provided ad libitum twice a day at about 9:30 A.M. and 3:30 P.M. daily.

\section{Feeds and feeding}

Experimental feeding was similar in all the groups except for the source and level of Se in the diet. The male Wistar rats were offered a basal diet to meet their nutrient requirements as per NRC [23] recommendations for rats. The basal diet consisted of ground maize grain (Zea mays) (27.5\%), Bengal gram (Cicer arietinum) (25\%), soybean (Glycine max) meal (21\%), wheat (Triticum aestivum) bran
(24\%), mineral mixture (2\%) with vitamin $\mathrm{A}$, and common salt $(0.5 \%)$. Weighed amount of the basal diet was provided at 9.00 A.M. daily to meet the nutrient requirements. The daily nutrient requirement was adjusted every week based on the BW of the animals While Group 1 (control) was fed a basal diet with no Se supplementation, in Groups 2 and 3, $150 \mathrm{ppb}$ Se was supplemented either as sodium selenite or Se nanoparticles, respectively. In Groups 4, 5, 6 and 7, Se was supplemented as its nanoparticles at $50 \%, 25 \%$, $12.5 \%$ and $6.25 \%$ levels respectively i.e., at $75 \mathrm{ppb}$, $37.5 \mathrm{ppb}, 18.75 \mathrm{ppb}$ and $9.375 \mathrm{ppb}$ levels respectively. In Groups 8 and 9, 300 ppb Se was supplemented either as Se nanoparticles or sodium selenite, respectively. Experimental feeding was conducted for a period of 91 days.

\section{Chemical analysis of feed samples}

Samples of feed offered were analyzed for proximate principles, phosphorous (P) [24] and calcium (Ca) [25].

\section{Estimation of Se in feed samples}

Weighed amount of dried feed samples were taken in different $100 \mathrm{~mL}$ Kjeldahl flasks, soaked overnight in 10-20 mL triple acid mixture of nitric acid, sulfuric acid and perchloric acid (4:2:1), and digested. Selenium was estimated in the triple acid digested samples using atomic absorption spectrophotometer model 4141 (Electronic Corporation of India Limited, Hyderabad, India) in air acetylene flame along with vapor generation (hydride generator) assembly.

\section{Preparation of selenium nanoparticles}

Selenium nanoparticles were synthesized as per the methods described by Ingole et al [26] and Chen et al [27]. The size of the obtained Se nanoparticles ranged from $35 \mathrm{~nm}$ to $50 \mathrm{~nm}$ as determined by transmission electron microscopy (TEM). TEM characterization was performed with a JEOL-JEM-1011 electron microscope, by dropping the sample suspension in ethanol on copper $(\mathrm{Cu})$ grid coated with a thin amorphous carbon film [28]. The concentration of Se was estimated using atomic absorption spectrophotometer model 4141 (ECIL, Hyderabad, India) along with vapor generation assembly.

\section{Blood analysis \\ Collection of blood and separation of serum and plasma}

After the completion of 70 days of experimental feeding, about $2 \mathrm{~mL}$ of blood was collected from each animal through cardiac puncture in the morning (before watering and feeding) and was taken into clean and dry test tube and kept in slanting position for $45 \mathrm{~min}$ to separate out the serum.

\section{Estimation of blood biochemical constituents}

All the blood biochemical parameters were estimated using diagnostic kits manufactured by Span Diagnostic Limited, Surat, India. 


\section{Serum glucose}

Serum glucose was estimated by glucose oxidase (GOD) and POD method as described by Henry [29]. Glucose was oxidized by GOD to gluconic acid and hydrogen peroxide. In a subsequent POD catalyzed reaction, the oxygen liberated was accepted by the chromogen system to give a red colored quinone amine compound. The red color so developed was measured at $505 \mathrm{~nm}$ and was directly proportional to glucose concentration (mg/dL in blood serum).

\section{Serum total protein (TP) and albumin}

Serum TP and albumin were estimated by Biuret and bromocresol green (BCG) dye binding method [30]. Serum protein binds to copper ions in an alkaline medium of Biuret reagent and produced a purple color complex, whose absorbance at $555 \mathrm{~nm}$ was proportional to protein concentration. Serum albumin binds to BCG in acidic condition and produced a green color, whose absorbance was measured at $630 \mathrm{~nm}$ and the concentration, was expressed as g/dL in blood serum.

\section{Serum globulin}

It was calculated by subtracting serum albumin from TP and expressed as g/dL in blood serum.

\section{Serum total cholesterol}

Cholesterol in the blood serum was determined by the method of Wybenga et al. [31]. Cholesterol present in serum reacted with a hot solution of the ferric perchlorate, ethyl acetate and sulfuric acid and gave a lavender colored complex, whose absorbance was measured at $560 \mathrm{~nm}$.

\section{Monitoring of the immune response}

At the end of 91 days of experimental feeding, humoral immune responses of the animals in the different groups were assessed by standard tube agglutination test (STAT).

\section{Assessment of humoral immune response}

Seven animals from each group were inoculated intramuscularly with a single dose $(0.5 \mathrm{~mL})$ of Pasteurella multocida oil adjuvant vaccine. The blood samples were collected at $0,7,14,21$ and 28 days of post vaccination for humoral immune response. About $1.0 \mathrm{~mL}$ of blood was collected from each animal through cardiac puncture in clean labeled tubes and the harvested serum was carefully transferred to the clean labeled plastic vials and stored in deep freezer $\left(-20^{\circ} \mathrm{C}\right)$ for further analysis.

\section{STAT}

Serial two fold dilutions of serum samples were prepared in normal saline. $0.5 \mathrm{~mL}$ of formalinized plain antigen of which the optical density was adjusted to brown opacity tube No.: 2 was added to $0.5 \mathrm{~mL}$ of diluted test samples in test tubes. The tubes were shaken well, and overnight incubation was done at $37^{\circ} \mathrm{C}$. STAT titer was expressed as the reciprocal of the highest dilution showing 50\% clearing.

\section{Statistical analysis}

All the data generated in the above experiments were statistically analyzed using 17th version of Statistical Package for Social Science (SPSS), (SPSS USA) [32] computer package. For comparison of groups, Generalized linear model ANOVA procedure and Duncan's multiple range tests [33] were used.

\section{Results}

\section{Chemical composition of the basal diet}

The chemical composition of the basal diet offered to male Wistar rats is presented in Table-1. The percent of different nutrients in the basal diet on dry matter basis was almost similar to the National Research Council [23] recommendations for rats. The selenium content in the basal diet was very low being $0.08 \mathrm{ppm}$.

\section{Blood biochemical parameters}

The mean blood serum glucose, serum total cholesterol, serum TP, serum albumin, serum globulin, and $A: G$ ratio after 70 days of experimental feeding in different groups are presented in Table-2.

The mean values of serum glucose and serum TP were comparable $(p>0.05)$ in the nine groups and were within the normal range, indicating that the supplementation of selenium nanoparticles up to $300 \mathrm{ppb}$ had no effect on these parameters.

The mean values of serum total cholesterol were significantly $(\mathrm{p}<0.001)$ lowered in all the Se supplemented Wistar rats compared to control the group. However, they were within the normal range (40-130 mg/dL) in rats.

The mean values of serum albumin were comparable $(p>0.05)$ in the nine experimental groups and also within the normal range. However, the mean serum globulin level was significantly $(\mathrm{p}<0.05)$ higher in Group 3 followed by Groups 2, 4, 5, 6, 8, and 9 as compared to control the group. The A:G ratio was also significantly $(\mathrm{p}<0.05)$ lowered in Group 3 compared to other experimental groups.

\section{Humoral immune response}

The serum antibody production against formalin inactivated P. multocida vaccine in Wistar rats at different periods (days post vaccination) as measured by STAT is presented in Table- 3 .

Table-1: Chemical composition of the basal diet offered to male Wistar rats.

\begin{tabular}{lc}
\hline Nutrients & \% $\mathbf{D M B}$ \\
\hline Organic matter & 95.28 \\
Crude protein & 22.66 \\
Ether extract & 4.56 \\
Total ash & 4.72 \\
Crude fiber & 7.75 \\
Nitrogen-free extract & 60.31 \\
Calcium & 1.50 \\
Phosphorus & 0.66 \\
Selenium & $0.08 \mathrm{ppm}$ \\
\hline DMB=Dry matter basis &
\end{tabular}

Veterinary World, EISSN: 2231-0916 
Table-2: Blood serum biochemical profile in different groups of male Wistar rats.

\begin{tabular}{|c|c|c|c|c|c|c|c|c|c|c|c|}
\hline \multirow[t]{2}{*}{ Attributes } & \multicolumn{9}{|c|}{ Groups } & \multirow[t]{2}{*}{ SEM } & \multirow[t]{2}{*}{ p value } \\
\hline & 1 & 2 & 3 & 4 & 5 & 6 & 7 & 8 & 9 & & \\
\hline Glucose $(\mathrm{mg} / \mathrm{dL})$ & 84.0 & 86.0 & 85.5 & 83.5 & 84.6 & 85.7 & 83.8 & 84.1 & 85.3 & 0.47 & 0.866 \\
\hline Total cholesterol $(\mathrm{mg} / \mathrm{dL}) *$ & $120^{c}$ & $95^{\mathrm{b}}$ & $85^{\mathrm{a}}$ & $84^{a}$ & $92^{b}$ & $94^{\mathrm{b}}$ & $101^{b}$ & $88^{a}$ & $97^{b}$ & 2.28 & $<0.001$ \\
\hline Total protein $(\mathrm{g} / \mathrm{dL})$ & 6.55 & 6.64 & 6.85 & 6.24 & 6.76 & 6.87 & 6.31 & 6.59 & 6.63 & 0.11 & 0.598 \\
\hline Albumin $(\mathrm{g} / \mathrm{dL})$ & 4.47 & 3.84 & 3.82 & 3.84 & 3.87 & 4.11 & 4.32 & 4.24 & 4.18 & 0.23 & 0.001 \\
\hline Globulin $(\mathrm{g} / \mathrm{dL}) *$ & $2.08^{a}$ & $2.80^{\mathrm{b}}$ & $3.03^{c}$ & $2.40^{\mathrm{b}}$ & $2.89^{b}$ & $2.76^{b}$ & $1.99^{a}$ & $2.35^{b}$ & $2.45^{b}$ & 0.21 & 0.002 \\
\hline A: G ratio* & $2.15^{\mathrm{e}}$ & $1.37^{\mathrm{b}}$ & $1.26^{\mathrm{a}}$ & $1.60^{c}$ & $1.34^{\mathrm{b}}$ & $1.49^{c}$ & $2.17^{e}$ & $1.80^{\mathrm{d}}$ & $1.71^{\mathrm{d}}$ & 0.14 & 0.021 \\
\hline
\end{tabular}

* Means bearing different superscripts in a row differ significantly $(p<0.05), A: G=A l b u m i n:$ globulin ratio, SEM=Standard error of mean

Table-3: Anti-P. multocida $\left(P_{52}\right) \log _{10}$ STAT titer in the sera of Wistar rats in different groups.

\begin{tabular}{|c|c|c|c|c|c|c|c|}
\hline \multirow[t]{2}{*}{$\begin{array}{l}\text { Group } \\
\text { (G) }\end{array}$} & \multicolumn{6}{|c|}{$\begin{array}{l}\text { Period (days post } \\
\text { vaccination) ( } P \text { ) }\end{array}$} & \multirow[t]{2}{*}{ p value } \\
\hline & 0 & 7 & $14 *$ & $21 *$ & 28* & Mean & \\
\hline 1 & ND & $1.23^{\mathrm{a}}$ & $1.75^{\mathrm{a}}$ & $1.98^{a}$ & $1.90^{\mathrm{a}}$ & $1.71^{\mathrm{a}}$ & $G<0.001$ \\
\hline 2 & ND & $1.75^{c}$ & $1.98^{\mathrm{a}}$ & $2.20^{c}$ & $2.05^{b}$ & $2.00^{\mathrm{b}}$ & $P<0.001$ \\
\hline 3 & ND & $1.98^{c}$ & $2.51^{c}$ & $2.73^{d}$ & $2.58^{c}$ & $2.45^{d}$ & $G \times P<0.001$ \\
\hline 4 & ND & $1.82^{c}$ & $2.20^{c}$ & $2.46^{c}$ & $2.38^{b}$ & $2.20^{c}$ & \\
\hline 5 & ND & $1.83^{c}$ & $2.05^{b}$ & $2.43^{c}$ & $2.35^{c}$ & $2.17^{c}$ & \\
\hline 6 & ND & $1.60^{\mathrm{b}}$ & $1.98^{\mathrm{a}}$ & $2.16^{\mathrm{b}}$ & $2.06^{b}$ & $1.94^{\mathrm{b}}$ & \\
\hline 7 & ND & $1.68^{c}$ & $1.90^{\mathrm{a}}$ & $2.13^{\mathrm{b}}$ & $2.04^{\mathrm{b}}$ & $1.94^{\mathrm{b}}$ & \\
\hline 8 & ND & $1.70^{c}$ & $2.10^{c}$ & $2.30^{c}$ & $2.20^{c}$ & $2.09^{c}$ & \\
\hline 9 & ND & $1.72^{c}$ & $2.20^{c}$ & $2.32^{c}$ & $2.26^{c}$ & $2.13^{c}$ & \\
\hline SEM & ND & 0.05 & 0.05 & 0.04 & 0.04 & 0.04 & \\
\hline
\end{tabular}

SEM $=$ Standard error of mean, ND=Not detectable as there was absence of agglutination in the test tubes. * Means bearing different superscripts in a column differ significantly $(p<0.001)$, STAT $=$ Standard tube agglutination test, P. multocida=Pasteurella multocida

It was observed that the serum antibody titer was significantly $(\mathrm{p}<0.001)$ higher in all the Se supplemented groups compared to control the group. It was further observed that on 21st day, the antibody titer values were significantly $(\mathrm{p}<0.001)$ higher in Group 3 followed by Groups 4, 5, 8 and 9 compared to control and other Se supplemented groups, indicating that selenium nanoparticles supplementation at $150 \mathrm{ppb}$ had highest effect on improving the humoral immune response in male Wistar rats.

\section{Discussion}

\section{Blood serum biochemical profile}

The supplementation of selenium either as Se nanoparticles or sodium selenite in the basal diet had no effect on serum glucose, serum TP and serum albumin in male Wistar rats. Contrary to our findings, Singh et al. [34] observed low blood glucose concentration in buffalo calves fed wheat straw containing high Se $(8.54 \mathrm{ppm})$ throughout the experiment. Ebrahimi et al. [35] also reported decreased plasma glucose concentration in Holstein calves fed with $0.3 \mathrm{ppm}$ of selenium as Sel-plex for 120 days. On the contrary, Nayyar et al. [36] reported significantly higher level of blood glucose in anestrous buffalo heifers supplemented with vitamin E + Se as compared to control. Similarly Mohapatra et al. [37] reported that supplementation of $0.3 \mathrm{ppm}$ nano Se in layer chicks up to
8 weeks post feeding significantly increased serum glucose levels compared to control.

However our results are supported by Shinde et al. [38] who observed that supplementation of vitamin E (300 IU) and Se (0.3 ppm) or both in the diet had no effect on serum glucose levels in buffalo calves. Yang et al. [39] too observed that serum glucose and TP levels were non-significant in $0.3 \mathrm{ppm}$ organic Se supplemented broiler chicks after 42 days post feeding compared to control the group. Similarly, Chung et al. [40] reported that the supplementation of 0.25 ppm of organic or inorganic selenium in Korean goats for 5 weeks had no effect on plasma glucose level. Mudgal et al. [41] also reported that feeding of 0.3 ppm of selenium for 120 days in buffalo calves had no effect on serum glucose concentrations. Dominguezvara et al. [42] too observed that feeding of $0.3 \mathrm{ppm}$ organic Se to Rambouillet sheep for 95 days had no effect on plasma glucose concentration.

It was further observed that Se supplementation remarkably lowered serum total cholesterol levels in Wistar rats with the highest impact in Se nanoparticles supplemented groups (Table-2), which was also dose dependent. Similar to our results, in rats, Se supplementation has been reported to increase low-density lipoprotein (LDL) receptor activity [43] and decrease the 3-OH-methyl-glutaryl CoA reductase expression [44] leading to decreased plasma LDL cholesterol and total cholesterol levels [45]. Also, Mohapatra et al. [37] reported that supplementation of 0.3 ppm nano Se in layer chicks up to 8 weeks post feeding significantly lowered serum cholesterol levels compared to control. On the contrary, Yang et al. [39] reported that total cholesterol level was non-significant in 0.3 ppm organic Se supplemented broiler chicks after 42 days post feeding compared to control the group.

The lowered A:G ratio and increased serum globulin levels are indicative of immunity status of the animals, and therefore the addition of selenium nanoparticles at 150 ppb level and other Se supplemented groups had an enhanced effect on the immune status of the animals with the best results with $150 \mathrm{ppb}$ Se nanoparticles.

In contrast to the present findings, no effect was observed in serum globulin levels which might 
be due to either very low (0.1 ppm) [46] or very high (8.54 ppm) levels of Se supplementations [34]. Similarly Yang et al. [39] reported that serum globulin level was non-significant in 0.3 ppm organic Se supplemented broiler chicks after 42 days post feeding compared to control the group.

However, similar to our results, supplementation of $0.2 \mathrm{ppm}$ Se in buffalo heifers increased serum globulin levels and reduced albumin level and $A: G$ ratio [47]. Similar to our results, an increased globulin and reduced levels of albumin and $A: G$ ratio was observed in male buffalo calves supplemented with $0.3 \mathrm{ppm}$ of Se [41]. Similarly, Mohapatra et al. [37] reported that supplementation of $0.3 \mathrm{ppm}$ nano Se in layer chicks up to 8 weeks post feeding significantly increased TP and serum globulin levels and also significantly lowered A:G ratio compared to control.

\section{Humoral immune response}

Selenium supplementation in the basal diet as either Se nanoparticles or sodium selenite enhanced the humoral immune response of Wistar rats compared to control the group. The highest immune response in $150 \mathrm{ppb}$ Se nanoparticles supplemented group indicated its supremacy among different levels of nanoparticles supplemented groups and also indicated that Se nanoparticles had a better efficacy than sodium selenite in enhancing the immune status of Wistar rats.

Contrary to our observations, there was no effect on the immunological response against Pasteurella haemolytica vaccination in steers given a single intramuscular dose of $25 \mathrm{mg}$ Se [48]. Similarly, there was no effect of supplementation of $1 \mathrm{ppm}$ Se over control diet ( $0.41 \mathrm{ppm}$ Se) on antibody titer against sheep red blood cells in crossbred beef cattle [49]. However, in these experiments, the basal diet itself had a quite high level of Se, and probably for that reason, they did not get any effect due to further Se supplementation. Basal diet in our experiment had comparatively lower levels of Se (0.08 ppm), which might have been responsible for the positive effect on humoral immune response in the rats on different levels of Se nanoparticle supplementation.

Similar to our results, it was observed that antibody mediated immune response was significantly higher in 0.15 and $0.30 \mathrm{ppm}$ Se supplemented groups as compared to control group in growing lambs [50], but there was no significant difference between the two Se-supplemented groups. It was also observed that both cellular and humoral immunity were significantly increased in layer chicks supplemented with $0.3 \mathrm{ppm}$ nano Se after 8 weeks of post feeding [37]. Similarly Cai et al. [51] reported that supplementation of nano Se up to the level of 0.3ppm in broiler chicks 42 days post feeding resulted in significant increase in the IgG and IgM levels compared to control. Male buffalo calves supplemented with 0.3 ppm Se exhibited significantly higher humoral immune response compared to control the group [41,52].

\section{Conclusion}

Supplementation of Se nanoparticles at the level of $150 \mathrm{ppb}$ in the basal diet significantly improved the mean serum globulin level and reduced A:G ratio and also improved the humoral immune response in male Wistar rats compared to $150 \mathrm{ppb}$ and $300 \mathrm{ppb}$ levels of sodium selenite and $300 \mathrm{ppb}$ of Se nanoparticles respectively. It was concluded that among the different Se sources (inorganic and nanoparticles) and levels (0-300 ppb), its supplementation at $150 \mathrm{ppb}$ level as nanoparticles gave the best performance in terms of improved humoral immune status in male Wistar rats.

\section{Author's Contributions}

SJB, AKG, RSD and SS designed the experiment. SJB conducted the research experiment. SJB, AKG, RSD and SS drafted and revised the manuscript. All the authors read and approved the final manuscript.

\section{Acknowledgment}

The authors are thankful to the Director, Indian Veterinary Research Institute, Izatnagar, India, for providing all the necessary facilities to carry out this research work. Financial assistance from Indian Council of Agricultural Research provided to the first author (SJB) in the form of Senior Research Fellowship is also gratefully acknowledged.

\section{Competing I nterests}

The authors declare that they have no competing interests.

\section{References}

1. Pappas, A.C. and Zoidis, E. (2012) The role of selenium in chicken physiology: New insights. In: Kapur, I. and Mehra, A., editors. Chickens: Physiology, Diseases and Farming Practices. Nova Science Publishers Inc., New York, USA. p51-69.

2. Abd El-Ghany, H. and Tortora-Perez, J.L. (2010) The importance of selenium and the effects of its deficiency in animal health. Small Rumin. Res., 89: 185-192.

3. Schrauzer, G.N. and Surai, P.F. (2009) Selenium in human, animal nutrition: Resolved, unresolved issues. A partly historical treatise in commemoration of the fiftieth anniversary of the discovery of the biological essentiality of selenium, dedicated to the memory of Klaus Schwarz (1914-1978) on the occasion of the thirtieth anniversary of his death. Crit. Rev. Biotechnol., 29(1): 2-9.

4. Pilarczyk, B., Jankowiak, D., Tomza- Marciniak, A., Pilarczyk, R., Sablik, P., Drozd, R., Tylkowska, A. and Skolmowska, M. (2012) Selenium concentration and glutathione peroxidase (GSH-Px) activity in serum of cows at different stages of lactation. Biol. Trace Elem. Res., 147: $91-96$

5. Ebeid, T.A. (2012) Vitamin E and organic selenium enhances the antioxidative status and quality of chicken cockerel semen under high ambient temperature. Br. Poult. Sci., 53: 708-714.

6. Sadeghian, S., Kojouri, G.A. and Mohebbi M. (2012) Nanoparticles of selenium as species with stronger physiological effects in sheep in comparison with sodium selenite. Biol. Trace Elem. Res., 146: 302-308. 
7. Saad, M.B., Gertner, L.R., Bona, T.D. and Santin, E. (2009) Selenium influence in the poultry immune response - Review. Recent Pat. Food Nutr. Agric., 1(3): 243-247.

8. Ozbal, S., Erbil, G., Kocdor, H., Tugyan, K., Pekcetin, C. and Ozogul, C. (2008) The effects of selenium against cerebral ischemia-reperfusion injury in rats. Neurosci. Lett., 438: 265-269.

9. Zhou, X., Wang, Y., Gu, Q. and Li, W. (2009) Effect of different dietary selenium source (selenium nanoparticle and selenomethionine) on growth performance, muscle composition and glutathione peroxidase enzyme activity of crucian carp (Carassius auratus gibelio). Aquaculture, 291: 78-81.

10. Zhou, X. and Wang, Y. (2011) Influence of dietary nano elemental selenium on growth performance, tissue selenium distribution, meat quality, and glutathione peroxidase activity in Guangxi Yellow chicken. Poult. Sci., 90: 680-686.

11. Vendeland, S.C., Deagen, J.T., Butler, J.A. and Whange, P.D. (1994) Uptake of selenite, selenomethionine and selenate by brush border membrane vesicle isolated from rat small intestine. Biometals, 7: 305-312.

12. Spallholz, J.E. (1994) On the nature of selenium toxicity and carcinostatic activity. Free Radic. Bio. Med., 17: 45-64.

13. Federal Register (2002) Food additive permitted in feed and drinking water: Selenium yeast. Fed. Regist., 67: 46850-46851.

14. Jiang, Z.Y., Lin, Y.C., Zhou, G.L., Luo, L.H., Jiang, S.Q. and Chen, F. (2009) Effects of dietary selenomethionine supplementation on growth performance, meat quality and antioxidant property in yellow broilers. J. Agric. Food Chem., 57: 9769-9772.

15. EEC. (2006) Commission Regulation (EC) No 1750/2006 of $27 \mathrm{Nov}, 2006$. Concerning the authorization of selenomethionine as a feed additive.

16. Hu, C.H., Li, Y.L., Xiong, L., Zhang, H.M., Song, J. and Xia, M.S. (2012) Comparative effects of nano elemental selenium and sodium selenite on selenium retention in broiler chickens. Anim. Feed Sci. Technol., 177: 204-210.

17. Shi, L.G., Yang, R.J., Yue, W.B., Xun, W.J., Zhang, C.X., Ren, Y.S., Shi, L. and Lei, F.L. (2010) Effect of elemental nano-selenium on semen quality, glutathione peroxidase activity, and testis ultrastructure in male Boer goats. Anim. Reprod. Sci. 118(2-4): 248-254.

18. Rezvanfar, M.A., Rezvanfar, M.A., Shahverdi, A.R., Ahmadi, A., Baeeri, M., Mohammadirad, A. and Abdollahi, M. (2013) Protection of cisplatin-induced spermatotoxicity, DNA damage and chromatin abnormality by selenium nanoparticles. Toxicol. Appl. Pharm., 266: 356-365.

19. Jia, X., Li, N. and Chen, J.A. (2005) A subchronic toxicity study of elemental Nano- Se in Sprague-Dawley rats. Life Sci., 76(17): 1989-2003.

20. Zhang, J.S., Wang, H.L., Yan, X.X. and Zhang, L.D. (2005) Comparison of short-term toxicity between Nano-Se and selenite in mice. Life Sci., 76(10): 1099-1109.

21. Zhang, J.S., Wang, X.F. and Xu, T.W. (2008) Elemental selenium at nano size (Nano-Se) as a potential chemo preventive agent with reduced risk of selenium toxicity: comparison with Se-methylselenocysteine in mice. Toxicol. Sci., 101(1): 22-31.

22. Wang, H., Zhang, J. and Yu, H. (2007) Elemental selenium at nano size possesses lower toxicity without compromising the fundamental effect on selenoenzymes: comparison with selenomethionine in mice. Free Radic. Bio. Med., 42(10): 1524-1533.

23. NRC. (1995) Nutrient Requirements of Laboratory Animals. $4^{\text {th }}$ Revised ed. The National Academies Press, Washington, D.C.

24. AOAC. (2012) Official Method of Analysis of AOAC International. 19th ed. Association of Analytical Communities International, Virginia, USA.

25. Talapatra, S.K., Ray, S.N. and Sen, K.C. (1940) Estimation of phosphorus, chlorine, calcium, magnesium, sodium and potassium in foodstuffs. Indian J. Vet. Sci. Anim. Husbandry. 10: 243-246.

26. Ingole, A.R., Thakare, S.R., Khati, N.T., Wankhade, A.V. and Burghate, D.K. (2010) Green synthesis of selenium nanoparticles under ambient condition. Chalcogenide Lett., 7: 485-489.

27. Chen, H., Yoo, J., Liu, Y. and Zhao, G. (2011) Green synthesis and characterization of Se nanoparticles and nanorods. Electron. Mater. Lett., 7: 333-336.

28. Shah, C.P., Singh, K.K., Kumar, M. and Bajaj, P.N. (2010) Vinyl monomers-induced synthesis of polyvinyl alcohol-stabilized selenium nanoparticles. Mater. Res. Bull. 45: 56-62.

29. Henry, R.J. (1963) Standard Methods of Clinical Chemistry. $1^{\text {st }}$ ed. Harper and Row Publishing Company, New York, USA.

30. Dumas, B.T., Watson, W.A. and Briggs, H.G. (1971) Albumin standards and the measurement of serum albumin with bromocresol green. Clin. Chim. Acta., 31: 87-96.

31. Wybenga, D.R., Pileggi, V.J., Dirstine, P.H. and Giorgio, J.D. (1970) Direct manual determination of serum total cholesterol with a single stable reagent. Clin. Chem., 16(12): 980-984.

32. SPSS Version 17.0. (2010) Base Application Guide 7.5. Statistical Package for Social Science, USA-7.

33. Steel, R.G.D. and Torrie, J.H. (1980) Principles and procedures of statistics. A Biometrical Approach. $2^{\text {nd }}$ ed. McGraw-Hill International Book Company, New Delhi, India.

34. Singh, R., Randhawa, S.S. and Dhillon, K.S. (2002) Changes in blood biochemical and enzyme profile in experimental chronic selenosis in buffalo calves (Bubalus bubalis). Indian J. Anim. Sci., 72: 230-232.

35. Ebrahimi, M., Towhidi, A. and Nikkhah, A. (2009) Effect of organic selenium on thermo metabolism, blood chemical composition and weight gain in Holstein suckling calves. Asian Aust. J. Anim., 7: 984-992.

36. Nayyar, S., Gill, V.K., Malik, V.S., Roy, K.S. and Singh, R. (2003) Vitamin E and selenium improve the blood biochemical composition of anoestrous buffalo heifers. Indian $J$. Anim. Sci., 73: 654-656.

37. Mohapatra, P., Swain, R.K., Mishra, S.K., Behera, T., Swain, P., Mishra, S.S., Behura, N.C., Sabat, S.C., Sethy, K., Dhama, K. and Jayasankar, P. (2014) Effects of dietary nano selenium on tissue selenium deposition, antioxidant status and immune functions in layer chicks. Int. J. Pharmacol., 10: 160-167.

38. Shinde, P.L., Dass, R.S., Garg, A.K. and Bhadane, K.P. (2008) Effect of vitamin E and selenium supplementation on growth, nutrient utilization and their balance in male buffalo calves. Anim. Nutr. Feed Technol., 8: 135-143.

39. Yang, Y.R., Meng, F.C., Wang, P., Jiang, Y.B., Yin, Q., Chang, J., Zuo, R.Y., Zeng, Q.H. and Liu, J.X. (2012) Effect of organic and inorganic selenium supplementation on growth performance, meat quality and antioxidant property of broilers. Afr. J. Biotechnol., 11: 3031-3036.

40. Chung, J.Y., Kim, J.H., Ko, Y.H. and Jang, I.S. (2007) Effect of dietary supplemented inorganic and organic selenium on antioxidant defence systems in the intestine, serum, liver and muscle of Korean native goats. Asian Aust. J. Anim., 20: 52-59.

41. Mudgal, V., Garg, A.K., Dass, R.S. and Varshney, V.P. (2008) Effect of selenium and copper supplementation on blood metabolic profile in male buffalo (Bubalus bubalis) calves. Biol. Trace Elem. Res., 121(1): 31-38.

42. Dominguez-Vara, I.A., Gonzalez-Munoz, S.S., Pinos-Rodriguez, J.M., Borquez-Gastelum, J.L., Barcena-Gama, R., Mendoza-Martinez, G., Zapata, L.E. and Landois-Palencia, L.L. (2009) Effects of feeding selenium-yeast and chromium-yeast to finishing lambs on growth, carcass characteristics, and blood hormones and metabolites. Anim. Feed Sci. Technol., 152: 42-49. 
43. Dhingra, S. and Bansal, M.P. (2006a) Attenuation of LDL receptor gene expression by selenium deficiency during hypercholesterolemia. Mol. Cell Biochem., 282(1-2): 75-82.

44. Dhingra, S. and Bansal, M.P. (2006b) Modulation of hypercholesterolemia-induced alterations in apolipoprotein B and HMG-CoA reductase expression by selenium supplementation. Chem. Biol. Interact., 161(1): 49-56.

45. Yang, K.C., Lee, L.T., Lee, Y.S., Huang, H.Y., Chen, C.Y. and Huang, K.C. (2010) Serum selenium concentration is associated with metabolic factors in the elderly: a cross-sectional study. Nutr. Metab.,7: 38.

46. Arthur, J.R., Morrice, P.C. and Beckett, G.J. (1988) Thyroid hormone content in selenium deficient and selenium sufficient cattle. Res. Vet. Sci., 45(1): 122-123.

47. Ganie, A.A., Baghel, R.P.S., Mudgal, V. and Sheikh, G.G. (2012) Effect of selenium supplementation on blood metabolic profile of buffalo heifers. Indian J. Anim. Res., 46: 407-409.47.

48. Droke, E.A. and Loerch, S.C. (1989) Effects of parenteral selenium and vitamin $\mathrm{E}$ on performance, health and humoral immune response of steers new to the feedlot environment. J. Anim. Sci., 67(5): 1350-1359.

49. Nicholson, J.W.G., Bush, R.S. and Allen, J.G. (1993) Antibody response of growing beef cattle fed silage diet with and without selenium supplementation. Can. J. Anim. Sci., 73: 355-365.

50. Kumar, N., Garg, A.K., Dass, R.S., Chaturvedi, V.K., Mudgal, V. and Varshney, V.P. (2009) Selenium supplementation influences growth performance, antioxidant status and immune response in lambs. Anim. Feed Sci. Technol., 153: 77-87.

51. Cai, S.J., Wu, C.X., Gong, L.M., Song, T., Wu, H. and Zhang, L.Y. (2012) Effects of nano-selenium on performance, meat quality, immune function, oxidation resistance, and tissue selenium content in broilers. Poult. Sci., 91(10): 2532-2539.

52. Shinde, P.L., Dass, R.S., Garg, A.K. and Chaturvedi, V.K. (2007) Immune response and plasma alpha tocopherol and selenium status of male buffalo (Bubalus bubalis) calves supplemented with vitamin E and selenium. Asian Aust. J. Anim. 20: 1539-1545. 